\title{
Clinical management of behavioral characteristics of Prader-Willi syndrome
}

This article was published in the following Dove Press journal:

Neuropsychiatric Disease and Treatment

9 April 2010

Number of times this article has been viewed

\author{
Alan Y Ho \\ Anastasia Dimitropoulos \\ Department of Psychology, Case \\ Western Reserve University, \\ Cleveland, OH, USA
}

Correspondence:Anastasia Dimitropoulos Department of Psychology,

Case Western Reserve University,

Cleveland, OH, USA

Email anastasia.dimitropoulos@case.edu
Abstract: Prader-Willi syndrome (PWS) is a complex neurodevelopmental disorder caused by an abnormality on the long arm of chromosome 15 (q11-q13) that results in a host of phenotypic characteristics, dominated primarily by hyperphagia and insatiable appetite. Characteristic behavioral disturbances in PWS include excessive interest in food, skin picking, difficulty with a change in routine, temper tantrums, obsessive and compulsive behaviors, and mood fluctuations. Individuals with PWS typically have intellectual disabilities (borderline to mild/moderate mental retardation) and exhibit a higher overall behavior disturbance compared to individuals with similar intellectual disability. Due to its multisystem disorder, family members, caregivers, physicians, dieticians, and speech-language pathologists all play an important role in the management and treatment of symptoms in an individual with PWS. This article reviews current research on behavior and cognition in PWS and discusses management guidelines for this disorder.

Keywords: Prader-Willi syndrome; neurodevelopment, hyperphagia, disability

\section{Introduction}

First described in 1956 by Prader, Labhart, and Willi, Prader-Willi syndrome (PWS) is a complex neurodevelopmental disorder that affects approximately 1 in 20,000 births with no distinguishing sex, race, or social status association. ${ }^{1}$ Individuals with PWS are typically short, obese, possess small hands and feet, and have dysmorphic features such as a narrow bifrontal diameter, full cheeks, and almond shaped eyes. ${ }^{2}$ In the neonatal period, diminished fetal activity, hypotonia, and feeding difficulty persist followed by hyperphagia, delayed psychomotor development, early onset obesity, incomplete sexual development in adolescence, sleep apnea, intellectual disabilities, and a behavioral profile that includes obsessive, compulsive, oppositional, and defiant behaviors. ${ }^{3}$ Individuals with PWS typically have intellectual disabilities (borderline to mild/moderate mental retardation) and exhibit a higher overall behavior disturbance compared to individuals with intellectual disability of unknown etiology. ${ }^{4}$ Due to the combination of hypotonia and intellectual disabilities, individuals with PWS also have speech and language difficulties. ${ }^{5}$ Risk factors for mortality in PWS include severe obesity, obstructive sleep apnea, upper respiratory tract infections (URI), aspiration, and tonsilor/adenoid hypertrophy. ${ }^{6}$ While those with intellectual disability (ID) have a higher mortality rate than in the general population, Einfeld and colleagues found that individuals with PWS have six times greater risk of death than other individuals with ID with obesity being the greatest risk factor. ${ }^{7}$ 
PWS is caused by the absence of expression of the paternally active genes in the proximal arm of chromosome 15 . Approximately $70 \%$ of the cases are due to the deletion of the paternally inherited chromosome 15 (q11-q13 region), 25\% due to maternal uniparental disomy (m-UPD) of chromosome 15 , and the rest are due to either a methylation imprinting defect or a translocation microdeletion. ${ }^{8-10}$ Individuals with paternal deletion can be further subdivided into Type I deletions (involving breakpoints BP1 and BP3 and is relatively longer - approximately $5 \mathrm{MB}$ in size) and Type II deletions (involving breakpoints BP2 and BP3 and is relatively shorter - approximately $500 \mathrm{~kb}$ smaller). ${ }^{11}$ Diagnostic criteria for PWS, which includes an inclusive listing of symptoms and a scoring system, was first developed in 1993 and still remains useful in informing and raising detection of the syndrome. ${ }^{2}$ However, cytogenetic and molecular techniques are used to confirm diagnosis. Fluorescent in situ hybridization (FISH), a cytogenetic technique that can identify and localize the presence or absence of specific DNA sequences on chromosomes, detects nearly all persons with deletions in the 15 (q11-q13 region). ${ }^{12}$ Additionally DNA methylation analysis detects methylation pattern characteristics with a sensitivity and specificity of nearly $100 \% .{ }^{13}$ Current recommendation is for all newborns with persistent hypotonia to first undergo methylation analysis to test for PWS. ${ }^{14,15}$ If methylation analysis is positive, a FISH test should be performed to ascertain whether PWS is caused by paternal deletion or m-UPD. ${ }^{15}$ While certain features of PWS are highly prevalent across genetic subtypes, recent research suggests that the deletion or m-UPD genetic subtypes may exhibit different risks for psychotic disorders. ${ }^{16-18}$ Furthermore, they may not exhibit problem behaviors with the same frequencies or severities. ${ }^{19-21}$

\section{Behavior and cognition}

Considered to have a specific behavioral phenotype, ${ }^{22,23}$ typical behavioral disturbances in PWS include excessive interest in food, skin picking, difficulty with change in routine, temper tantrums, obsessive and compulsive behaviors, and mood fluctuations. ${ }^{24-27}$ Older children and adults with PWS exhibit elevated compulsions as measured by the compulsivity subscale of the Yale-Brown Obsessive Compulsive Scale. ${ }^{28,29}$ When compared with other children with developmental delay, 2-7 year-old children with PWS engage in more compulsive behaviors, and these behaviors are related to the severity of hyperphagia symptomatology. ${ }^{30}$ The obsessive and compulsive behaviors found in PWS tend to be ritualistic behaviors such as hoarding, ordering and arranging objects, insistence on routines, and repetitive speech, rather than the more common symptoms found in obsessive-compulsive disorder (OCD) such as checking and cleaning or preoccupations with sexual, religious, or aggressive impulses.$^{31}$ Furthermore, unlike OCD, those with PWS do not appear to perform ritualistic behaviors aimed at reducing their anxiety or discomfort but may do so because it is enjoyable. ${ }^{32}$ Interestingly, the types of repetitive behaviors seen in PWS are similar to those common in autism spectrum disorders (ASD). ${ }^{31,33,34}$ Recent evidence suggests that there may be increased prevalence of ASD diagnosis in PWS (see Dimitropoulos and Schultz ${ }^{31}$ for recent review) with a specific elevated risk in PWS m-UPD cases. ${ }^{35}$ The symptoms of autism are believed to be caused by many genes on multiple chromosomes, but one of the most frequent genetic abnormalities resides on the same critical region for PWS, Chromosome 15(q11-q13). ${ }^{36,37}$ While individuals with the m-UPD genotypic subtype may be at an increased risk for autistic symptomatology, psychosis, and sleep disorders, ${ }^{16}$ those with the deletion subtype have greater rates of skin picking, distress, mood lability, food stealing, ${ }^{38}$ withdrawal, sulking, nail biting, hoarding, and overeating. ${ }^{19}$ High rates of attention-deficit hyperactivity disorder (ADHD) symptoms, insistence on sameness, and their association with maladaptive conduct problems have also been reported with severity being more pronounced in individuals with paternal deletion relative to those with m-UPD. ${ }^{17}$ Regardless of genetic subtype, weaknesses have been shown in socialization in addition to a relative strength in daily living skills that may be due to heightened interest in food and food preparation. ${ }^{23}$

Many individuals with PWS need psychiatric support during several periods of their lives when dealing with compulsions, depression, or psychotic episodes. Previous studies have shown that $6 \%-28 \%$ of individuals with PWS exhibited psychotic symptoms with an age of onset ranging from 13 to 26 years and a prevalence rate higher than individuals with other IDs..$^{18,22,39,40}$ Furthermore, individuals with PWS show age-related increases in internalizing problems such as anxiety, sadness, and a feeling of low selfworth. ${ }^{41}$ Recent studies have found an association between m-UPD and psychotic illness. ${ }^{16,18,39}$ Boer and colleagues ${ }^{16}$ found that the m-UPD subtype of PWS had more severe psychotic disorders than those with the deletion subtype of PWS. While those with the deletion subtype of PWS have less severe psychotic disorders, gender has been shown to be significantly related to maladaptive behavior in those with PWS deletion. ${ }^{42}$ Males with the deletion subtype are at greater risk for aggressive behavior, depression, dependent 
personality disorder, and overall severity of psychopathology than females with PWS deletion. ${ }^{42}$ Recent research has aimed to further specify the PWS phenotype by exploring differences between Type I and Type II deletions. Butler et al reported lower adaptive behavior scores in individuals with Type I deletion and greater externalizing behaviors and more severe compulsions in individuals with Type II deletions ${ }^{43}$ Hartley and colleagues indicated people with Type I deletion had significantly higher Reiss depression (physical signs) scores than people with Type II deletion. ${ }^{42}$ In addition, Zarcone and colleagues found more washing/cleaning compulsions in those with Type I deletions and more rereading and rewriting compulsions in those with Type II deletions. ${ }^{44}$ However, these results have yet to be replicated. Milner and colleagues found differences between Type I deletion and Type II deletion to be minimal although people with Type I deletion performed more poorly on all measures of ability. ${ }^{45}$ In a more recent study, Dykens and Roof found no differences between deletion subtypes. ${ }^{11}$

Cognitively, most individuals with PWS function in the mild mental retardation range with a mean IQ in the 60 s to low 70s. ${ }^{46,47}$ However, regardless of measured IQ, many of these individuals cannot perform at their predicted IQ score in everyday functioning if their emotional and behavioral problems are left untreated. ${ }^{48}$ The combination of food-related preoccupations and numerous maladaptive behaviors makes it difficult for individuals with PWS to perform to their IQ potential. Compared to individuals with ID, those with PWS show a distinctive profile of cognitive strengths and weaknesses. ${ }^{49,50}$ Short-term memory is more severely affected than long-term memory ${ }^{51,52}$ while deficits in auditory processing is more pronounced than visual processing. ${ }^{53}$ Deficits in executive tasks have also been observed. ${ }^{48,50}$ Individuals with PWS also have difficulty interpreting social information. In the Social Attribution Task, individuals with PWS performed significantly worse than an IQ-matched group and on par with individuals with pervasive developmental disorders. ${ }^{54}$

Previous research suggested that individuals with PWS may have had strengths in visuospatial ability due to their adept puzzle skills. ${ }^{46,55}$ However, new findings suggest this may not be true. ${ }^{56}$ While past research used visuospatial tasks resembling puzzles, Verdine and colleagues ${ }^{56}$ used tasks testing visuospatial ability used in typically developing populations: spatial perception, mental rotation, and spatial visualization. ${ }^{57}$ Verdine and colleagues ${ }^{56}$ found that individuals with PWS performed worse than the mental age matched group and thus, these abilities are not responsible for their jigsaw puzzle skills. While individuals with PWS on average tend to perform more poorly on visuospatial ability tasks compared to both mental age and chronological age matched controls, ${ }^{46,56}$ individuals with the deletion subtype of PWS appear to perform better at visual processing tasks than the m-UPD subtype. ${ }^{58}$ This relative sparing of visuospatial ability is not uniform though as the relative strength is seen only in the ventral stream (processes the surface characteristics of stimuli) and is accompanied by a deficit in the dorsal stream processing (processes position information in action). ${ }^{59}$ While Verdine and colleagues ${ }^{6}$ were not able to perform further subtype comparisons due to a limited sample size, it would be interesting to see if the pronounced, shape-based puzzle solving style in individuals with PWS was driven by the performance of the deletion subtype.

Research has also shown further differences in cognitive profile between the different genotypes. Whittington and colleagues ${ }^{20}$ found that individuals with m-UPD PWS had better verbal abilities, but poorer coding abilities than the deletion subgroup. This finding is consistent with the finding that the m-UPD PWS group has significantly higher verbal IQ scores than individuals with the deletion subtype of PWS. ${ }^{21}$ Recent research examining differences between Type I and Type II deletions show that individuals with Type I deletions scored significantly lower on math and reading compared to individuals with Type II deletions. ${ }^{43}$

Speech and language development is often delayed and problematic in PWS. ${ }^{46,60,61}$ The severity differs greatly among individuals with PWS. There are those who are nonverbal and there are those who acquire normal speech and language by adulthood. ${ }^{5}$ In a typically developing child, word understanding essentially begins from birth and expressive language follows soon after at 3 months. By the age of 12 months, most children can say at least two words: "mama" and "dada." On the other hand, children with PWS do not verbally display vocabulary until the age of 18 months and sometimes as late as 6 years. ${ }^{5}$ Common features seen in PWS include poor speech-sound development, reduced oral motor skills, and language deficits. ${ }^{60}$ In addition to speech difficulties, individuals with PWS may have language problems such as deficits in grammar, narrative abilities, and pragmatics. ${ }^{46,60}$ Poor speech-sound development of individuals with PWS may be a result of abnormal saliva (thick and viscous saliva), ${ }^{2}$ hypotonia, and cognitive deficits. ${ }^{5}$ Reduced oral motor skills, due to hypotonia, also contributes to poor speech-sound development as the rate of speech, quality of the voice, and the ability to articulate words is affected. With regard to language development, individuals with PWS frequently demonstrate poor receptive and expressive 
language skills, with expressive language showing greater deficits than receptive skills. ${ }^{5,61,62}$ Individuals with PWS also have poor narrative skills which negatively affect how they can communicate with others in both a social and work environment. ${ }^{5}$ These poor language skills may be the result of a deficit in auditory short-term memory, ${ }^{52}$ poor temporal sequencing skills, ${ }^{46}$ and poor auditory processing skills. ${ }^{5}$ In addition, individuals with PWS have difficulty maintaining a topic, showing appropriate empathetic speech, and turn taking in a conversation. ${ }^{5}$

Maladaptive behavior, cognitive impairment, and speech language development have important implications on the childhood and long-term functioning of an individual. Understanding the cognitive strengths and difficulties underlying the maladaptive behavior will allow for better management of the syndrome. One of the most significant stressors for family caregivers is the extent of emotional and behavioral problems exhibited by children and adults with developmental disabilities. ${ }^{63,64}$ Behavioral issues often impact individuals with PWS and their family more than any other aspect of the disorder. Therefore, it is important to not only manage and treat the most striking features of PWS such as hyperphagia and weight-related issues first, but to also be aware of the secondary behavioral and cognitive implications of behavioral therapy and medical treatments such as growth hormone and psychotropic medications.

\section{Behavioral management}

Due to the range of problems and variability of symptom severity across individuals with PWS, management of PWS is age-dependent, multidisciplinary, and utilizes a problembased approach to cater to each individual. While there is no cure for PWS, with early diagnosis and a proactive approach, individuals with PWS can live a full and meaningful life.

Early assessment and intervention by a speech-language pathologist is critical for developing future communication skills. Even in infancy, early intervention focusing on improving oral motor skills can improve feeding. ${ }^{5}$ Continued assessment of speech-sounds, receptive/expressive language skills, voice, and fluency is important throughout an individual's life as each individual's development may vary greatly from person to person. ${ }^{5}$ Therapeutic methods to improve articulation and language include exercises to improve muscle control of the mouth, tongue and throat, and techniques to improve pronunciation, increase vocabulary skills and sentence formation. In more severe cases of poor speech skills, other forms of communication such as sign language or communication boards may be helpful as an inability to communicate may lead to greater frustration and problem behaviors. Moreover, intervention should emphasize pragmatics along with managing behavioral problems as these maladaptive behaviors hinder satisfactory pragmatic language ability.

Management of behavioral problems is most effective if detected early as these difficulties may increase with age. Studies to date have shown the frequencies and severity of maladaptive behaviors are not uniform across age groups. Steinhausen and colleagues ${ }^{65}$ found that increased age was associated with higher scores on the DBC-P total behavior problem score (TBPS) along with the Disruptive/Antisocial, Communication Disturbance, Anxiety, and Social Relating subscales of the DBC-P. Age-related increases have also been found in the overall number of nonfood compulsive symptoms in individuals with PWS aged 5 to 47 years old. ${ }^{28}$ In addition, Dykens and colleagues ${ }^{66}$ found that the frequency of overeating, skin-picking, stubbornness, hoarding, ordering of items, and externalizing symptoms (tantrums, food theft and lying) increased with age in individuals with PWS in their teens, 20s, and 30s. Actually, those in their 20 s had the highest rate of maladaptive behaviors, social problems, and compulsive symptoms possibly due to new stressors such as transitioning from school to a work environment and a more acute awareness of their differences relative to those of their same age. ${ }^{41}$ Adaptive behavior is often related to behavioral problems as individuals with an ID may engage in maladaptive behaviors as a means of communication. ${ }^{67}$ Moreover, research has shown that coping with stress, regulating negative affect, and resisting temptations require self-control, a limited and consumable resource. ${ }^{68}$ Thus, continuous self-control efforts, in addition to increased stress, will degrade the executive component of self-inhibition and over time lead to increased problem behaviors.

With regard to socialization in those with PWS, weakness has been shown in individuals aged under 30 years which may likely be due to inadequate coping skills. ${ }^{66}$ In fact, Hartley and colleagues ${ }^{42}$ found individuals with PWS aged 20-29 years had significantly higher aggressive behavior scores than those aged $12-19$ years and 30-45 years. The combination of adolescence and early adulthood being a period of emotional lability, independence seeking, and a period where difficulties with socialization abound as peers mature more rapidly makes this time especially challenging. In older adults, both maladaptive and compulsive behaviors, including noncompliance and skin picking, diminish significantly. This may be due to unknown physiological 
factors or the benefits of years of sustained behavior and dietary interventions. ${ }^{41}$ Furthermore, as individuals' age, goals, preferences, motivation, and cognitive processes such as attention and memory change as they do in the general population. ${ }^{69}$ Whether or not there are distinct phenotypic changes in PWS during older adulthood has not been well researched.

Because food-related preoccupations and foraging may underlie behavior and emotional disturbances, food-related issues should be targeted and addressed first before behavioral management of nonfood-related issues becomes attainable. ${ }^{70}$ Given unrestricted access to food, those with PWS will consume approximately three times more calories than that of individuals matched on age and body mass index. ${ }^{71}$ In addition, individuals with PWS show a strong preference for sweet foods rather than salty, plain, or sour foods ${ }^{72}$ and they also have a clear preference for high fat or carbohydrate foods to foods with lower caloric values. ${ }^{73,74}$ When food is unavailable, individuals with PWS may eat inedible food such as pet food due to abnormalities in satiety response and early returns of hunger after meals. ${ }^{75-77}$ If overeating is uncontrolled, it may lead to life-threatening obesity and increase risk for multiple medical conditions such as Type 2 diabetes, respiratory problems, and cardiovascular disease. ${ }^{41}$ Thus, working with a dietician is essential. Functional neuroimaging of individuals with PWS suggest this impairment of normal satiety response may be due to a hypothalamic dysfunction. ${ }^{78,79}$ Moreover, recent research suggests that the constant overeating and the persistent heightened interest in high-calorie foods may be related to abnormally increased neural activation in brain regions involved in appetite, food motivation, and reward. ${ }^{80}$ According to Holland and Wong, ${ }^{81}$ individuals with PWS may not have the mental capacity to make decisions on eating. Thus, fundamental management of food-related issues involves 24-hour-a-day environmental control such as keeping all food under lock and key, disciplined supervision of food access, while instituting a low-calorie, well-balanced diet concordant with regular exercise. ${ }^{82,83}$ Interestingly, studies have found that BMI is significantly, negatively, related to aggressive behavior in both the deletion subtype and m-UPD subtypes while BMI was also significantly negatively related to symptoms of paranoia in the deletion subtype. ${ }^{42}$ In short, individuals with lower BMI are at an increased risk of problem behaviors for reasons that are not clear. One possibility is consistent with the limited strength model of self-control where selfregulatory strength appears to be a limited resource that can be fatigued. Coping with stress may lead to a decreased ability to exert self-control. ${ }^{68}$ Thus, resisting a constant urge to eat food results in poorer performance on vigilance tasks in the non-PWS population, and results in a reduced ability to self-regulate one's emotions and behaviors. ${ }^{84,85}$ Further research is needed to clarify these findings. ${ }^{42}$

Recent findings indicate that dietary treatment of reduced fat and modified carbohydrate meals starting at the 2 nd year of life and continued until the age of 10 years was effective in avoiding excessive weight gain in patients with PWS compared to individuals with PWS without this specific dietary intervention. ${ }^{86}$ On the other hand, findings indicated that patients on this strict dietary intervention had a significant decrease in height. Schmidt and colleagues ${ }^{86}$ reason that individuals with PWS need a surplus of weight to achieve normal growth in height and thus, having a normal BMI, at a young age, would stunt the individuals' final height. Carrel and colleagues ${ }^{87}$ found that treatment for growth hormone (GH) deficiency in PWS shows a dose-dependent effect on height, body composition, and resting energy expenditure. ${ }^{79}$ It is possible a combination of the reduced fat and modified carbohydrate meals along with GH treatment may result in increased height along with normal BMI. This is the first long-term study with a follow-up report about the effectiveness of early dietary intervention in children with PWS.

Some studies have reported effective intervention for problem behaviors in PWS, using applied behavior analysis (ABA) procedures. To date, research using ABA in PWS has been limited to single case or small sample size experiments. However, ABA procedures show promise as ABA is the primary method of treating aberrant behavior in individuals who have autism. ${ }^{88,89}$ Page and colleagues ${ }^{91}$ eliminated food stealing in two children with PWS by using an ABA procedure called Differential Reinforcement of Other Behavior (DRO). In DRO, positive reinforcement is provided only when the target behavior is not displayed for a specified period of time. DRO has been one of the most used reinforcement procedures for the reduction of problem behavior in people who have intellectual disabilities. ${ }^{91}$ In Page and colleagues' study, the children were given tokens that could be exchanged for snacks when they did not exhibit food-stealing behavior during timed intervals. ${ }^{90}$ A token-based program based on DRO was also effectively implemented in a separate study in hospital settings, a group home, and an apartment-living arrangement setting. ${ }^{92}$ Using another form of ABA, Maglieri and colleagues showed that food stealing in a 14-year-old girl with moderate mental retardation and PWS could be greatly reduced by combining verbal reprimands with a procedure to bring food stealing 
behavior under the control of stickers. ${ }^{93}$ Stickers were placed on certain containers filled with cookies and a reprimand was paired with taking food from containers with a sticker. In other words, the stickers were used as a way to label prohibited foods and the reprimand was used to discourage food taking. Maglieri and colleagues ${ }^{93}$ then placed a sticker on a refrigerator containing pudding cups to see if this skill could be generalized and this was equally effective in reducing covert food stealing. Because continuous supervision is difficult and individuals with PWS are skilled at covertly stealing food, this intervention may be effective for some individuals in reducing food-stealing behavior.

One of the most prevalent characteristics of PWS, regardless of genetic subtype, is skin picking, with the front of the legs and head being disproportionately targeted in this population. ${ }^{94}$ Dykens and Kasari administered the Child Behavior Checklist ${ }^{95}$ to parents of 43 children with PWS aged between 4 and 19 years and found that $95 \%$ of the children had problems with skin picking. ${ }^{96}$ Symons and colleagues ${ }^{94}$ found that $82 \%$ of people surveyed with PWS in their sample $(n=62)$ showed some kind of skin-picking. Among children and adolescents, females are more inclined to skin pick than males. ${ }^{41}$ This gender difference is also seen in individuals with chronic skin picking (CSP) in the non-PWS population. ${ }^{97}$ Skin picking in both populations may cause open sores to bleed and as a result, leave scarring, bruising, and lead to secondary infections. Cognitive behavioral interventions such as habit-reversal training (HRT), which involves three primary components (awareness training, competing response training, and social support), have shown promise in treating CSP ${ }^{98,99}$ A recent pilot study examining the efficacy of acceptance-enhanced behavior therapy, a combination of HRT with acceptance and commitment therapy (ACT), found this psychosocial intervention to be effective in reducing skin picking in CSP. ${ }^{100}$ Empirical investigation of these cognitive behavioral interventions has yet to be performed in the PWS population. In the short term, immediate treatment such as topical antibiotics and bandaging may decrease skin picking and the chances of infections.

While not as common as skin picking, approximately $15 \%$ of adolescents and adults with PWS also display rectal picking ${ }^{101}$ with an increased prevalence in those with UPD. ${ }^{11}$ Rectal picking has serious medical complications including blood loss, trauma to the anal sphincter, and perirectal abscess. ${ }^{102}$ Treatment includes keeping the fingernails short, limiting the time spent in the bathroom to reduce opportunities for rectal picking, and behavior modification. While the few studies reporting ABA procedures in treating food-related behaviors show promise, behavioral treatment of self-injurious behavior among individuals with PWS has not been well documented.

Due to slightly different behavioral profiles present in the different genotypes; and because there are individual differences in the presence or absence of symptoms and the severity of symptoms, it is important to tailor assessments and interventions to each individual with PWS. Currently, little is known about the cause(s) of maladaptive behavior or other variables that are associated with the prevalence and severity of maladaptive behavior in individuals with PWS. While empirical studies of behavioral treatment are lacking, ABA interventions with individuals with PWS show promise and further evaluative research is warranted. However, before developing a behavior intervention plan, it is important to conduct a functional assessment to determine what factors are influencing the maladaptive behavior, so that a proper intervention or combination of interventions can be formulated. Information from a functional assessment helps yield more effective treatments than treatments without this assessment. ${ }^{103}$ Once a stable outcome has been achieved, gradually withdrawing procedures to support behavioral change is warranted as to increase independence in the individual with PWS.

\section{Growth hormone}

Those that suffer from severe growth hormone deficiency (GHD) show an impairment of growth hormone regulation due to abnormal hypothalamic functioning. ${ }^{104-107}$ In contrast to children with simple obesity, there is no enhancement of growth velocity despite onset of obesity in individuals with PWS. During adolescence, the growth rate declines due in part to inefficient testosterone and estrogen levels, resulting in the absence of the pubertal growth spurt. ${ }^{9,108}$ Long-term GH therapy in patients with PWS has been shown to increase: height velocity and final adult height potential, lean body mass, muscle strength, and level of activity, and to decrease fat mass. ${ }^{109-114}$ As a result of decreased fat mass and increased lean body mass, GH treatment has also shown to improve pulmonary function in children with PWS. ${ }^{111,115}$ While the benefits of GH therapy are well documented, the behavioral and cognitive implications of GH treatment are not as unequivocal in the PWS population. Those that suffer from severe GHD from other etiologies suffer from a negative quality of life and possibly psychological symptoms such as poor memory, social withdrawal, and depression. ${ }^{116}$ However, these problems improve with GH therapy. ${ }^{116} \mathrm{GH}$ therapy in other populations is known to increase energy levels, increase 
sexual function, and improve weight management, all effects that have behavioral and possibly cognitive implications.

Collectively, studies have generally shown promise regarding the effects of $\mathrm{GH}$ therapy on behavior, cognition, and quality of life in persons with PWS. While earlier studies ${ }^{117,118}$ have found beneficial effects on intellectual speed and flexibility, Haqq and colleagues ${ }^{111}$ found no influence of GH intervention on cognitive function in children with PWS. However, in a pilot study evaluating behavior in young adults with PWS at baseline, during and after GH treatment, Hoybye, Thoren, and Bohm reported beneficial effects on mental speed, flexibility, and motor performance after 6 to 18 months of GH treatment and a decrease in overall functioning back to baseline levels when $\mathrm{GH}$ treatment was discontinued at either 3 or 6 months after cessation. ${ }^{119}$ Recent studies have also suggested that early GH therapy in infants with PWS improves cognition. In a randomized, controlled study, Myers and colleagues ${ }^{120}$ randomized 25 infants and toddlers with PWS, ages 4-37 months to either 2 years of GH therapy or 1 year of observation without GH therapy then 1 year of GH treatment. The 2-year GH-treated PWS group had increased rate of language and cognitive development along with increased head circumference. Consistent with these findings, Festen and colleagues ${ }^{121}$ also found improvement in mental development after 1 year of treatment in a randomized, controlled trial in infants and toddlers aged between 6 months and 3 years. Whether these cognitive improvements are just short-term benefits or are due to longterm effects such as changes in underlying brain structure is unknown. Cognitive improvements as an indirect result of improved muscle function allowing children to better able explore their surroundings cannot be ruled out. Regardless of whether these benefits are direct changes to underlying brain structures or as a function of indirect results, these findings are promising. Employing longitudinal designs to examine sustained benefits are warranted given these findings.

Behavioral changes have also been noted as a result of $\mathrm{GH}$ treatment in children with PWS. Eiholzer and colleagues ${ }^{106}$ found, through parent reporting, that GH treatment increased alertness and enjoyment in physical activity in children with PWS. Similarly, Whitman and colleagues ${ }^{122}$ found a significant reduction of depressive symptoms from baseline to time 1 (12 months) and retained at 24 months among those treated with GH. However, for children aged 11 years and younger, a significant increase in attention-deficit/hyperactivity symptoms was observed. Haqq and colleagues ${ }^{111}$ also found a significant increase in the hyperactivity scale on the Behavior Assessment System for Children and subjective parent reports also reported increased alertness in GH treated individuals with PWS. ${ }^{123}$

$\mathrm{GH}$ therapy is currently considered to be a standard element of the comprehensive care children with PWS receive. ${ }^{124}$ A recent multicenter study found that along with improving a number of physical characteristics previously mentioned before, no adverse effects of long-term GH treatment in a large group of prepubertal children was found. ${ }^{125}$ Since July 2000, the United States Food and Drug Administration (FDA) approved GH for children with PWS regardless of the presence of growth hormone deficiency. However, in Tauber and colleagues' review of 64 cases of death in children with PWS, the authors suggest that the first 9 months of GH therapy has a higher risk period of death compared to later months. ${ }^{6}$ As a result, increased vigilance may be warranted during early stages of such treatment. For those with pre-existing conditions such as URI, tonsilor/adenoid hypertrophy, severe obesity, and high insulin-like growth factor I (IGF-I), close monitoring to worsening of these symptoms is necessary, especially in individuals undergoing GH treatment. Despite this, convincing evidence that children treated with $\mathrm{GH}$ have a higher mortality rate than untreated patients or that GH therapy is directly involved in patients' deaths is not present. ${ }^{6,124}$ On the other hand, GH treatment may even improve sleep-disordered breathing, which includes sleep apnea, in individuals with PWS. ${ }^{111,126,127}$

\section{Pharmacological and surgical treatment}

Treatment with numerous psychotropic medications such as antidepressants, antipsychotics, appetite suppressants, and others have shown limited effectiveness in controlling hyperphagia and nonfood-related issues. There is no specific pharmacologic treatment for PWS specific behavioral disturbances. Hyperphagia in PWS is related to decreased satiation rather than increased hunger and as a result, appetite suppression medications have not been effective. ${ }^{76}$ Restrictive bariatric surgery has also not been effective in reducing hyperphagia or long-term weight reduction and has been associated with increased morbidity and mortality. ${ }^{128}$ Serotonin agonists (SSRIs) have been the most successful in reducing temper outbursts and improving compulsivity in PWS. ${ }^{129,130}$ Serotonin imbalance has been linked to repetitive behavior, obsessive and compulsive behavior, depression, anxiety, and self-injurious behavior in the non-PWS population. ${ }^{131}$ Holland and colleagues, ${ }^{23}$ through factor-analysis, found that skin-picking and mood swings were related and thus could have a common underlying etiologic mechanism. The use of 
fluoxetine in an adolescent with PWS has been reported in a case study, with improvement in bodyweight and decreased compulsive behavior. ${ }^{129}$ Hellings and Warnock reported that treatment with fluoxetine reduced skin picking behavior. ${ }^{130}$ In an 8-week open-label study primarily examining Topiramate as an appetite-regulating medication, Shapira and colleagues unexpectedly found that Topiramate did not reduce food-related behaviors but did reduce skin picking. ${ }^{132}$ These reports are in agreement with previous studies ${ }^{133-135}$ using SSRIs. On the other hand, Kohn and colleagues ${ }^{136}$ reported an aggravation in food-related symptoms and a consequent weight gain in an adolescent treated with fluoxetine and fluvoxamine. Studies to date have been small; controlled and randomized studies have yet to be performed. Future studies should explore the differential treatment effects of individuals with PWS based on subtyping and the potential efficacy of combined psychotherapy and pharmacology to improve outcome.

Given the prevalence of psychosis in PWS, families and caregivers should be vigilant for symptoms of this disorder as individuals age. It is particularly important to be aware that while psychosis is common in PWS, the prevalence rates are significantly higher in adults with UPD or imprinting defects. ${ }^{16,18,39}$ Because individuals with PWS have a lower tolerance for change or hardships in the immediate environment, it is important to assess the precipitating and perpetuating factors that may be causing a change in mood before an intervention is implemented. Currently, there are few research studies published on the efficacy and use of psychotropic medications in treating psychiatric illness in the PWS population. As a result, psychiatric illness in PWS is treated in a standard manner by identifying behaviors and symptoms for a psychiatric disorder and treating them as such, whether it is through cognitive behavioral strategies or through medication.

\section{Conclusion}

Beneficial effects on behavior and cognition have been shown thus far in small controlled studies and parent reports. Larger cohort studies and replication of results with parallel measurements would substantiate findings. To date, due to the rarity of the disorder, larger and more systematic studies on the management and treatment of behavior have been difficult to conduct. The benefits of GH therapy have shown to improve somatic symptoms both in the short and long-term in individuals with PWS. While aggravation of pre-existing conditions due to GH therapy have been found in some individuals; and should be closely monitored, the benefits of $\mathrm{GH}$ treatment are substantial as it not only improves physical characteristics and psychomotor development, but also has psychological and behavioral benefits with no known substantiated side effects.

On the other hand, it is important to remind parents and caregivers that GH treatment is not a panacea and long-term adaptation improvements are most effective with sustained behavioral intervention strategies that allow individuals with PWS to actively deal with their problems. Before developing a behavior intervention plan, a functional assessment should be conducted to determine what factors are influencing the maladaptive behavior so that a proper intervention or combination of interventions can be formulated. Food-related issues are the most debilitating and thus, management of food-related issues should be addressed first. This includes restricting access to food while instituting a low-calorie and well-balanced diet in concordance with regular exercise. ABA interventions with individuals with PWS show promise in managing and increasing independence in individuals with PWS. Not only is increased independency directly beneficial to the individual with PWS, but it also relieves some of the burden off of the family and/or caregivers. Pharmacological treatment, GH treatment, and surgery have yet to show positive effects in treating hyperphagia although anecdotal reports from parents and caretakers indicate the possibility that food intake may be easier to control with an individual on GH therapy.

Studies on the effectiveness of pharmacological medication in controlling PWS specific behaviors may have benefits to the patient, although some side effects have been reported. Furthermore, the benefits have been shown in uncontrolled studies with small sample sizes. Thus, pharmacological treatment should be used only with caution and in combination with psychiatric support and behavioral management. One of the most prevalent characteristics of PWS is skin picking. In the short term, immediate treatment such as topical antibiotics and bandaging may decrease skin picking and the chances of infections. In the long-term, acceptance-enhanced behavior therapy may be an effective method of decreasing self-injury. However, behavioral treatment of self-injurious behavior among individuals with PWS has not been well documented.

While speech and language skills differ greatly among individuals with PWS, early assessment and intervention by a speech-language pathologist is critical for developing future communication skills especially for those most severely affected. Early intervention focusing on improving oral motor skills can improve feeding in infancy. Later on, 
intervention should not only emphasize improvements in articulation and language, but also pragmatics, concurrently with managing behavioral problems, because maladaptive behaviors hinder satisfactory pragmatic language ability. Because PWS is a multisystem disorder, a multidisciplinary approach to treatment is recommended to achieve the best possible outcome for each individual. Primary care physicians should have active dialogue with the various specialists involved in management of this syndrome throughout the lifespan.

\section{Disclosures}

The authors report no conflicts of interest in this work.

\section{References}

1. Whittington JE, Holland AJ, Webb T, Butler J, Clarke D, Boer H. Population prevalence and estimated birth incidence and mortality rate for people with Prader-Willi syndrome in one UK Health Region. Journal of Medical Genetics. 2001;38(11):792-298.

2. Holm V, Cassidy S, Butler M, et al. Prader-Willi syndrome: Consensus diagnostic criteria. Pediatrics. 1993;91:398-402.

3. Maggio MC, Corsello M, Piccione M, Prio E, Giuffre M, Liotta A. Neonatal presentation of Prader-Willi syndrome. Personal Records. Minerva Pediatrica. 2007;59(6):817-823.

4. Curfs LM, Verhulst FC, Fryns JP. Behavioural and emotional problems in youngsters with Prader-Willi syndrome. Genetic Counseling. 1991;2:33-41.

5. Lewis BA, Freebairn L, Heeger S, Cassidy SB. Speech and language skills of individuals with Prader-Willi Syndrome. American Journal of Speech-Language Pathology. 2002;11:285-294.

6 Tauber M, Diene G, Molinas C, Hebert M. Review of 64 cases of death in children with Prader-Willi syndrome (PWS). American Journal of Medical Genetics Part A. 2008;146(7):881-887.

7. Einfeld SL, Kavanagh SJ, Smith A, Evans EJ, Tonge BJ, Taffe J. Mortality in Prader-Willi syndrome. American Journal of Mental Retardation. 2006;111(3):193-198.

8. Bittel DC, Butler MG. Prader-Willi syndrome: clinical genetics, cytogenetics and molecular biology. Expert Reviews in Molecular Medicine. 2005;7:1-20.

9. Butler MG, Meaney FJ. Standards for selected anthropometric measurements in Prader-Willi syndrome. Pediatrics. 1991;88:853-860.

10. Toth-Fejel S, Olson S, Gunter K, et al. The impact of imprinting: Prader-Willi syndrome resulting from chromosome translocation, recombination, and nondisjunction. American Journal of Human Genetics. 1996;58(5):1008-1016.

11. Dykens EM, Roof E. Behavior in Prader-Willi syndrome: relationship to genetic subtypes and age. The Journal of Child Psychology and Psychiatry. 2008;49(9):1001-1008.

12. ASHG/ACMG report. Diagnostic testing for Prader-Willi and Angelman syndromes: Report of the ASHG/CMG Test and Technology Transfer Committee. American Journal of Human Genetics. 1996;58: 1085-1089.

13. Cassidy SB, Schwartz S. Prader-Willi and Angelman syndromes. Disorders of genomic imprinting. Medicine (Baltimore). 1998;77(2): $140-151$.

14. Gunay-Aygun M, Schwartz C, O'Riordan MA, Cassidy SB. The changing purpose of Prader-Willi syndrome clinical diagnostic criteria and proposed revised criteria. Pediatrics. 2001;108:E92.

15. Monaghan KG, Wiktor A, Van Dyke DL. Diagnostic testing for Prader-Willi syndrome and Angelman syndrome: a cost comparison. Genetics in Medicine. 2002;4(5):448-450.
16. Boer H, Holland AJ, Whittington JE, Butler J, Webb T, Clarke D. Psychotic illness in people with Prader-Willi syndrome due to chromosome 15 maternal uniparental disomy. The Lancet. 2002;359:135-136.

17. Wigren M, Hansen S. ADHD symptoms and insistence on sameness in Prader-Willi syndrome. Journal of Intellectual Disability Research. 2005;49:449-456.

18. Verhoeven WM, Tuinier S, Curfs LM. Prader-Willi syndrome: the psychopathological phenotype in uniparental disomy. Journal of Medical Genetics. 2003;40(10):e112.

19. Dykens EM, Cassidy SB, King BH. Maladaptive behavior differences in Prader-Willi syndrome due to paternal deletion versus maternal uniparental disomy. American Journal of Mental Retardation. 1999;104:67-77.

20. Whittington JE, Holland AJ, Webb T, Butler J, Clarke D, Boer H. Cognitive abilities and genotype in a population-based sample of people with Prader-Willi syndrome. Journal of Intellectual Disability Research. 2004;48:172-188.

21. Roof E, Stone W, MacLean W, Feurer ID, Thompson T, Butler MG. Intellectual characteristics of Prader-Willi syndrome: comparison of genetic subtypes. Journal of Intellectual Disability Research. 2000;44(Pt 1):25-30.

22. Beardsmore A, Dorman T, Cooper SA, Webb T. Affective psychosis and Prader-Willi syndrome. Journal of Intellectual Disability Research. 1998;42(6):463-471.

23. Holland AJ, Whittington JE, Butler J, Webb T, Boer H, Clarke D. Behavioral phenotypes associated with specific genetic disorders: evidence from population-based study of people with Prader-Willi syndrome. Psychological Medicine. 2003;33:141-153.

24. Dykens EM, Cassidy SB. Prader-Willi syndrome: Genetic, behavioral, and treatment issues. Child and Adolescent Psychiatric Clinics of North America. 1996;5:913-927.

25. Einfeld SL, Smith A, Durvasula S, Florio T, Tonge BJ. Behavior and emotional disturbance in Prader-Willi syndrome. American Journal of Medical Genetics. 1999;82:123-127.

26. State MW, Dykens EM, Rosner B, Martin A, King BH. Obsessivecompulsive symptoms in Prader-Willi and "Prader-Willi-like" patients. Journal of American Academy of Child Adolescent Psychiatry. 1999;38:329-334.

27. Dimitropoulos A, Feurer I, Butler M, Thompson T. Emergence of compulsive behavior and tantrums in children with Prader-Willi syndrome. American Journal on Mental Retardation. 2001;106(1):39-51.

28. Dykens EM, Leckman JF, Cassidy SB. Obsessions and compulsions in Prader-Willi syndrome. Journal of Child Psychology and Psychiatry. 1996;37(8):995-1002.

29. Stein DJ, Keating J, Zar HJ, E H. A survey of the phenomenology and pharmacotherapy of compulsive and impulsive-aggressive symptoms in Prader-Willi syndrome. The Journal of Neuropsychiatry and Clinical Neurosciences. 1994;6:23-29.

30. Dimitropoulos A, Blackford J, Walden T, Thompson T. Compulsive behavior in Prader-Willi syndrome: Examining severity in early childhood. Research in Developmental Disabilities. 2006;27:190-202.

31. Dimitropoulos A, Schultz RT. Autistic-like Symptomatology in Prader-Willi Syndrome: A Review of Recent Findings. Current Psychiatry Reports. 2007;9:159-164.

32. Vitiello B, Spreat S, Behar D. Obsessive-compulsive disorder in mentally retarded patients. Journal of Nervous and Mental Disease. 1989;177(4):232-236.

33. Greaves N, Prince E, Evans DW, Charman T. Repetitive and ritualistic behaviour in children with Prader-Willi syndrome and children with autism. Journal of Intellectual Disability Research. 2006;50(Pt 2):92-100.

34. Descheemaeker MJ, Govers V, Vermeulen P, Fryns JP. Pervasive developmental disorders in Prader-Willi syndrome: The Leuven experience in 59 subjects and controls. American Journal of Medical Genetics A. 2006;140(11):1136-1142. 
35. Veltman MW, Craig EE, Bolton PF. Autism spectrum disorders in Prader-Willi and Angelman syndromes: a systematic review. Psychiatric Genetics. 2005;15(4):243-254.

36. Shroer RJ, Phelan MC, Michaelis RC, et al. Autism and maternally derived aberrations of chromosome 15q. American Journal of Medical Genetics. 1998;76(4):327-336.

37. Cook EH Jr, Courchesne RY, Cox NJ, et al. Linkage-disequilibrium mapping of autistic disorder, with 15q11-13 markers. American Journal of Medical Genetics. 1998;62(5):1077-1083.

38. Webb T, Whittington JE, Clarke D, Boer H, Butler J, Holland A. A study of the influence of different genotypes on the physical and behavioral phenotypes of children and adults ascertained clinically as having PWS. Clinical Genetics. 2002;62:273-281.

39. Vogels A, Matthigs G, Legius E, Devriendt K, Fryns JP. Chromosome 15 maternal uniparental disomy and psychosis in Prader-Willi syndrome. Journal of Medical Genetics. 2003;40:72-73.

40. Hiraiwa R, Maegaki Y, Oka A, Ohno K. Behavioral and psychiatric disorders in Prader-Willi syndrome: A population study in Japan. Brain and Development. 2007;29(9):535-542.

41. Dykens EM. Maladaptive and compulsive behavior in Prader-Willi syndrome: New insights from older adults. American Journal of Mental Retardation. 2004;109(2):142-153.

42. Hartley SL, Maclean WE Jr, Butler MG, Zarcone J, Thompson T. Maladaptive behaviors and risk factors among the genetic subtypes of Prader-Willi syndrome. American Journal of Medical Genetics A. 2005;136(2):140-145.

43. Butler MG, Bittel DC, Kibiryeva N, Talebizadeh Z, Thompson T. Behavioral differences among subjects with Prader-Willi syndrome and type I or type II deletion and maternal disomy. American Academy of Pediatrics. 2004;113:565-573.

44. Zarcone J, Napolitano D, Peterson C, et al. The relationship between compulsive behavior and academic achievement across three genetic subtypes of Prader-Willi syndrome. Journal of Intellectual Disabilities Research. 2007;51:478-487.

45. Milner KM, Craig EE, Thompson RJ, et al. Prader-Willi syndrome: Intellectual disabilities and behavioral features by genetic subtype. Journal of Child Psychology and Psychiatry. 2005;46: 1089-1096.

46. Dykens EM, Hodapp RM, Walsh K, Nash L. Profiles, correlates and trajectories of intelligence in individuals with Prader-Willi syndrome. Journal of American Academy of Child and Adolescent Psychiatry. 1992;31:1125-1130.

47. Curfs LM, Fryns JP. Prader-Willi Syndrome: a review with special attention to the cognitive and behavioral profile. Birth Defects Original Article Series. 1992;28:99-104.

48. Gross-Tsur V, Landau YE, Benarroch F, Wertman-Elad R, Shalev RS. Cognition, attention, and behavior in Prader-Willi syndrome. Journal of Child Neurology. 2001;16(4):288-290.

49. Bertella L, Girelli L, Grugni G, Marchi S, Molinar E, Semenza C. Mathematical skills in Prader-Willi Syndrome. Journal of Intellectual Disability Research. 2005;49:159-169.

50. Walley RM, Donaldson MDC. An investigation of executive function abilities in adults with Prader-Willi syndrome. Journal of Intellectual Disability Research. 2005;49:613-625.

51. Cassidy SB, Forsythe M, Heeger S, et al. Comparison of phenotype between patients with Prader-Willi syndrome due to deletion $15 \mathrm{q}$ and uniparental disomy 15. American Journal of Medical Genetics. 1997;68:433-440.

52. Conners FA, Rosenquist CJ, Atwell JA, Klinger LG. Cognitive strengths and weaknesses associated with Prader-Willi syndrome. Education and Training in Mental Retardation and Developmental Disabilities. 2000;35:442-449.

53. Curfs LM, Wiegers AM, Sommers JR, Borghgraef M, Fryns JP. Strengths and weaknesses in cognitive profile of youngsters with Prader-Willi syndrome. Clinical Genetics. 1991;40(6):430-434.

54. Koenig K, Klin A, Schultz R. Deficits in social attribution ability in Prader-Willi Syndrome. Journal of Autism and Developmental Disorders. 2004;34:573-582.
55. Gabel S, Tarter RE, Gavaler J, Golden W, Hegedus AM, Mair B. Neuropsychological capacity of Prader-Willi children: General and specific aspects of impairment. Applied Research in Mental Retardation. 1986;7:459-466.

56. Verdine BN, Troseth GL, Hodapp RM, Dykens EM. Strategies and correlates of jigsaw puzzle and visuospatial performance by persons with Prader-Willi Syndrome. American Journal on Mental Retardation. 2008;113(5):343-355.

57. Liben LS, Susman EJ, Finkelstein JW, et al. The effects of sex steroids on spatial performance: A review and an experimental clinical investigation. Developmental Psychology. 2002;38:236-253.

58. Fox R, Yang GS, Feurer ID, Butler MG, Thompson T. Kinetic form discrimination in Prader-Willi syndrome. Journal of Intellectual Disability Research. 2001;45:317-325.

59. Woodcock KA, Humphreys GW, Oliver C. Dorsal and ventral stream mediated visual processing in genetic subtypes of Prader-Willi syndrome. Neuropsychologia. 2009;47:2367-2373.

60. Akefeldt A, Akefeldt B, Gilberg C. Voice, speech and language characteristics of children with Prader-Willi syndrome. Journal of Intellectual Disability Research. 1997;41:302-311.

61. Kleppe SA, Katayama KM, Shipley KG, Foushee DR. The speech and language characteristics of children with Prader-Willi syndrome. Journal of Speech and Hearing Disorders. 1990;55:300-309.

62. Van Borsel J, Defloor T, Curfs LM. Expressive language in persons with Prader-Willi syndrome. Genetic Counseling. 2007;18(1):17-28.

63. Guralnick MJ, Hammond MA, Neville B, Connor RT. The relationship between sources and functions of social support and dimensions of child- and parent-related stress. Journal of Intellectual Disability Research. 2008;52(12):1138-1154.

64. Ha JH, Hong J, Seltzer MM, Greenberg JS. Age and gender differences in the well-being of midlife and aging parents with children with mental health or developmental problems: Report of a national study. Journal of Health and Social Behavior. 2008;49(3):301-316.

65. Steinhaussen HC, Eiholzer U, Hauffa BP, Malin Z. Behavioural and emotional disturbances in people with Prader-Willi syndrome. Journal of Intellectual Disability Research. 2004;48(1):47-52.

66. Dykens EM, Hodapp RM, Walsh K, Nash LJ. Adaptive and maladaptive behavior in Prader-Willi syndrome. Journal of the American Academy of Child and Adolescent Psychiatry. 1992;31:1131-1135.

67. Cipani E, Spooner F. Treating problem behaviors maintained by negative reinforcement. Research in Developmental Disabilities. 1997;18: 329-342.

68. Muraven M, Baumeister R. Self-regulation and depletion of limited resources: does self-control resemble a muscle? Psychological Bulletin. 2000;126(2):247-259.

69. Carstensen LL. The influence of a sense of time on human development. Science. 2006;312(5782):1913-1915.

70. Dimitropoulos A, Ho AY, Klaiman C, Koenig K, Schultz RT. A comparison of behavioral and emotional characteristics in children with autism, Prader-Willi Syndrome, and Williams Syndrome. Journal of Mental Health Research in Intellectual Disabilities. 2009;2: 220-243.

71. Zipf WB, Berntson GG. Characteristics of abnormal food-intake patterns in children with Prader-Willi syndrome and study of effects of naloxone. American Journal of Clinical Nutrition. 1987;26(2): 277-281.

72. Caldwell ML, Taylor RL. A clinical note on food preference of individuals with Prader-Willi syndrome: the need for empirical research. Journal of Mental Deficiency Research. 1983;27(Pt 1):45-49.

73. Glover D, Maltzman I, Williams C. Food preferences among individuals with and without Prader-Willi syndrome. American Journal of Mental Retardation. 1996;101(2):195-205.

74. Joseph B, Egli M, Koppekin A, Thompson T. Food choice in people with Prader-Willi syndrome: Quantity and relative preference. American Journal on Mental Retardation. 2002;107(2):128-135.

75. Dykens EM. Contaminated and unusual food combinations: what do people with Prader-Willi syndrome choose? Mental Retardation. 2000;38(2):163-171. 
76. Lindgren AC, Barkeling B, Hagg A, Ritzen EM, Marcus C, Rossner S. Eating behavior in Prader-Willi syndrome, normal weight, and obese control groups. Journal of Pediatrics. 2000;137(1):50-55.

77. Holland AJ, Treasure J, Coskeran P, Dallow J, Milton N, Hillhouse E. Measurement of excessive appetite and metabolic changes in PraderWilli syndrome. International Journal of Obesity and Related Metabolic Disorders. 1993;17(9):527-532.

78. Shapira NA, Lessig MC, He AG, James GA, Driscoll DJ, Liu Y. Satiety dysfunction in Prader-Willi syndrome demonstrated by fMRI Journal of Neurology, Neurosurgery, and Psychiatry. 2005;76(2): 260-262.

79. Holland A, Whittington J, Hinton E. The paradox of Prader-Willi syndrome: a genetic model of starvation. Lancet. 2003;362(9388): 989-991.

80. Dimitropoulos A, Schultz RT. Food-related Neural Circuitry in Prader-Willi Syndrome: Response to high- versus low-calorie foods. Journal of Autism and Developmental Disorders. 2008;38(9): 1642-1653.

81. Holland AJ, Wong J. Genetically determined obesity in Prader-Willi syndrome: the ethics and legality of treatment. Journal of Medical Ethics. 1999;25:230-236.

82. Hoffmann C, Aultman D, Pipes P. A nutrition survey of and recommendations for individuals with Prader-Willi syndrome who live in group homes. Journal of the American Dietetic Association. 1992;92(7):823-833.

83. Stadler DD. Nutritional Management of Prader-Willi Syndrome. 2 ed; 1995.

84. Green MW, Rogers PJ. Impaired cognitive functioning during spontaneous dieting. Psychological Medicine. 1995;25:1003-1010.

85. Green MW, Rogers PJ, Elliman NA, Gatenby SJ. Impairment of cognitive performance associated with dieting and high levels of dietary restraint. Physiology and Behavior. 1994;55:447-452.

86. Schmidt H, Pozza SB, Bonfig W, Schwarz HP, Dokoupil K. Successful early dietary intervention avoids obesity in patients with Prader-Willi syndrome: a ten year follow-up. Journal of Pediatric Endocrinology and Metabolism. 2008;21(7):651-655.

87. Carrel AL, Myers SE, Whitman BY, Allen DB. Benefits of long-term GH therapy in Prader-Willi syndrome: a 4 year study. Journal of Clinical Endocrinology and Metabolism. 2002;87(4):1581-1585.

88. Baer D, Wolf M, Risley R. Some still-current dimensions of applied behavior analysis. Journal of Applied Behavior Analysis. 1987;20:313-327.

89. Granpeesheh D, Tarbox J, Dixon DR. Applied behavior analytic interventions for children with autism: a description and review of treatment research. Annals of Clinical Psychiatry: Official Journal of the American Academy of clinical Psychiatrists. 2009;21(3):162-173.

90. Page TJ, Finney JW, Parrish JM, Iwata BA. Assessment and reduction of food stealing in Prader-Willi children. Applied Research in Mental Retardation. 1983;4:219-228.

91. Lennox DB, Miltenberger RG, Spengler P, Erfanian N. Decelerative treatment practices with persons who have mental retardation: A review of five years of the literature. American Journal on Mental Retardation. 1988;92:492-501.

92. Page TJ, Stanley AE, Richman GS, Deal RM, Iwata BA. Reduction of food theft and long-term maintenance of weight loss in a Prader-Willi adult. Journal of Behavior Therapy and Experimental Psychiatry. 1983;14(3):261-268.

93. Maglieri KA, DeLeon IG, Rodriquez-Catter V, Sevin BM. Treatment of covert food stealing in an individual with Prader-Willi syndrome. Journal of Applied Behavior Analysis. 2000;33:615-618.

94. Symons FJ, Butler MG, Sanders MD, Feurer ID, Thompson T. Selfinjurious behavior and Prader-Willi syndrome: behavioral forms and body locations. American Journal of Mental Retardation. 1999;104(3): 260-269.

95. Achenbach T. Manual for the Child Behavior Checklist. Burlington, VT; 1991.

96. Dykens E, Kasari C. Maladaptive behavior in Prader-Willi syndrome, Down syndrome, and nonspecific mental retardation. American Journal of Mental Retardation. 1997;102:228-237.
97. Bloch MR, Elliot M, Thompson H, Koran LM. Fluoxetine in pathologic skin-picking. Psychosomatics. 2001;42;314-319.

98. Teng EJ, Woods DW, MP T. Habit reversal as a treatment for chronic skin picking: A pilot investigation. Behavior Modification. 2006;30:411-422.

99. Twohig MP, Woods DW. Habit reversal as a treatment for chronic skin picking in typically developing adult male siblings. Journal of Applied Behavior Analysis. 2001;34:217-220.

100. Flessner CA, Busch AM, Heideman PW, Woods DW. Acceptance-enhanced behavior therapy (AEBT) for trichotillomania and chronic skin picking: exploring the effects of component sequencing. Behavior Modification. 2008;32(5):579-594.

101. Hanchett J. Skin picking and other forms of self-trauma in Prader-Willi syndrome. Gathered View. 1994:37.

102. Stokes JV, Luiselli JK. Applied behavior analysis assessment and intervention for health: threatening self-injury (rectal picking) in an adult with Prader-Willi syndrome. Clinical Case Studies. 2009;8(1):38-47.

103. Campbell J. Efficacy of behavioral interventions for reducing problem behavior in persons with autism: a quantitative synthesis of single-subject research. Research in Developmental Disabilities. 2003;24:120-138.

104. Brambilla P, Bosio L, Manzoni P, Pietrobelli A, Beccaria L, Chiumello G. Peculiar body composition in patients with Prader-LabhartWilli syndrome. American Journal of Clinical Nutrition. 1997;65: 1369-1374.

105. Eiholzer U, Bachmann S, l'Allemand D. Is there growth hormone deficiency in Prader-Willi Syndrome: Six arguments to support the presence of hypothalamic growth hormone deficiency in Prader-Willi syndrome. Hormone Research. 2000;53(Supplement 3):44-52.

106. Eiholzer U, Giosin R, Weinmann C, et al. Treatment with human growth hormone in patients with Prader-Labhart-Willi syndrome reduces body fat and increases muscle mass and physical performance. European Journal of Pediatrics. 1998;157(5):368-377.

107. Costeff H, Holm AV, Ruvalcaba R, J S. Growth hormone secretion in Prader-Willi syndrome. Acta Paediatrica Scandinavica. 1990;79(11):1059-1062.

108. Nagai T, Matsuo N, Kayanuma Y, et al. Standard growth curves for Japanese patients with Prader-Willi syndrome. American Journal of Medical Genetics. 2000;95:130-134.

109. Angulo MA, Castro-Magana M, Lamerson M, Arguello R, Accacha S, Khan A. Final adult height in children with Prader-Willi syndrome with and without human growth hormone treatment. American Journal of Medical Genetics. 2007;143:1456-1461.

110. Carrel AL, Meyers SE, Whitman BY, Allen DB. Sustained benefits of growth hormone on body composition, fat utilization, physical strength, and agility, and growth in Prader-Willi syndrome are dosedependent. Journal of Pediatric Endocrinology and Metabolism. 2001;14(8):1097-1105.

111. Haqq AM, Stadler DD, Jackson RH, Rosenfeld RG, Purnell JQ, LaFranchi SH. Effects of growth hormone on pulmonary function, sleep quality, behavior, cognition, growth velocity, body composition, and resting energy expenditure in Prader-Willi syndrome. Journal of Clinical Endocrinology Metabolism. 2003;88(5): 2206-2212.

112. Hoybye C. Five-years growth hormone $(\mathrm{GH})$ treatment in adults with Prader-Willi syndrome. Acta Paediatrica. 2007;96:410-413.

113. Lindgren AC, Ritzen EM. Five years of growth hormone treatment in children with Prader-Willi syndrome. Swedish National Growth Hormone Advisory Group. Acta Paediatrica Supplementum. 1999;88(433):109-111.

114. Mogul HR, Lee PDK, Whitman BY, et al. Growth hormone treatment of adults with Prader-Willi syndrome and growth hormone deficiency improves lean body mass, fractional body fat, and serum triiodothyronine without glucose impairment: results from the United States multicenter trial. Journal of Clinical Endocrinology Metabolism. 2008;93(4):1238-1245. 
115. Lindgren AC, Hellstrom LG, Ritzen EM, Milerad J. Growth hormone treatment increases $\mathrm{CO}(2)$ response, ventilation and central inspiratory drive in children with Prader-Willi syndrome. European Journal of Pediatrics. 1999;158(11):936-940.

116. Gilchrist FJ, Murray RD, Shalet SM. The effect of long-term untreated growth hormone deficiency (GHD) and 9 years of GH replacement on the quality of life (QoL) of GH-deficient adults. Clinical Endocrinology. 2002;57:363-370.

117. Mard G, Lundin K, Borg G, Jonsson B, Lindberg A. Growth hormone replacement therapy in adult hypopituitary patients with growth hormone deficiency: combined data from 12 European placebo-controlled clinical trials. Endocrinology and Metabolism. 1994; I(Suppl A):43-49.

118. Murray RD, Skillicorn CJ, Howell SJ, et al. Influences on quality of life in $\mathrm{GH}$ deficient adults and their effect on response to treatment. Clinical Endocrinology (Oxf). 1999;51(5):565-573.

119. Hoybye C, Thoren M, Bowhm B. Cognitive, emotional, physical, and social effects of growth hormone treatment in adults with Prader-Willi syndrome. Journal of Intellectual Disability Research. 2005;49(4):245-252.

120. Meyers SE, Whitman BY, Carrel AL, Moerchen V, Bekx MT, Allen DB. Two years of growth hormone therapy in young children with PraderWilli syndrome: physical and neurodevelopmental benefits. American Journal of Medical Genetics Part A. 2006;143A:443-448.

121. Festen DAM, Wevers M, Lindgren AC, et al. Mental and motor development before and during growth hormone treatment in infants and toddlers with Prader-Willi syndrome. Clinical Endocrinology (Oxf). 2008;68:919-925.

122. Whitman BY, Myers S, Carrel A, Allen D. The behavioral impact of growth hormone treatment for children and adolescents with Prader-Willi syndrome: a 2-year controlled study. Pediatrics. 2002;109(2):E35.

123. Myers SE, Whitman BY, Carrel AL, Moerchen V, Bekx MT, Allen DB. Two years of growth hormone therapy in young children with PraderWilli syndrome: physical and neurodevelopmental benefits. American Journal of Medical Genetics. 2007;143(5):443-448.

124. Lee PD. Disease management of Prader-Willi syndrome. Expert Opinion on Pharmacotherapy. 2002;3(10):1451-1459.

125. De Lind van Wijngaarden RF, Siemensma EP, Festen Da, et al. Efficacy and safety of long-term continuous growth hormone treatment in children with Prader-Willi syndrome. Journal of Clinical Endocrinology and Metabolism. 2009;94(11):4205-4215.
126. Festen DA, de Weerd AW, van den Bossche RA, Joosten K, Hoeve H, Hokken-Koelega AC. Sleep-related breathing disorders in prepubertal children with Prader-Willi syndrome and effects of growth hormone treatment. Journal of Clinical Endocrinology Metabolism. 2006;91(12):4911-4915.

127. Miller J, Silverstein J, Shuster J, Driscoll DJ, Wagner M. Short-term effects of growth hormone on sleep abnormalities in Prader-Willi syndrome. Journal of Clinical Endocrinology Metabolism. 2005;92(2):413-417.

128. Scheimann AO, Butler MG, Gourash L, Cuffari C, Klish W. Critical analysis of bariatric procedures in Prader-Willi syndrome. Journal of Pediatric Gastroenterology and Nutrition. 2008;46(1):80-83.

129. Dech B, Budow L. The use of fluoxetine in an adolescent with Prader-Willi syndrome. Journal of American Academy of Child Adolescent Psychiatry. 1991;30:298-302.

130. Hellings JA, Warnock JK. Self-injurious behavior and serotonin in Prader-Willi syndrome. Psychopharmacology Bulletin. 1994;30(2):245-250.

131. Murphy TK, Segarra A, Storch EA, Goodman WK. SSRI adverse events: how to monitor and manage. International Review of Psychiatry. 2008;20(2):203-208.

132. Shapira NA, Lessig MC, Lewis MH, Goodman WK, Driscoll DJ. Effects of topiramate in adults with Prader-Willi syndrome. American Journal of Mental Retardation. 2004;109(4):301-309.

133. Benjamin E, Buot-Smith T. Naltrexone and fluoxetine in Prader-Willi syndrome. Journal of American Academy of Child Adolescent Psychiatry. 1993;32:870-873.

134. Jerome L. Prader-Willi and bipolar illness. Journal of American Academy of Child Adolescent Psychiatry. 1993;32(4):876-877.

135. Warnock JK, Kestenbaum T. Pharmacologic treatment of severe skinpicking behaviors in Prader-Willi syndrome. Two case reports. Archives of Dermatology. 1992;128(12):1623-1625.

136. Kohn Y, Weizman A, Apter A. Aggravation of food-related behavior in an adolescent with Prader-Willi syndrome treated with fluvoxamine and fluoxetine. International Journal of Eating Disorders. 2001;30(1):113-117.
Neuropsychiatric Disease and Treatment

\section{Publish your work in this journal}

Neuropsychiatric Disease and Treatment is an international, peerreviewed journal of clinical therapeutics and pharmacology focusing on concise rapid reporting of clinical or pre-clinical studies on a range of neuropsychiatric and neurological disorders. This journal is indexed on PubMed Central, the 'PsycINFO' database and CAS, and is the official

\section{Dovepress}

journal of The International Neuropsychiatric Association (INA). The manuscript management system is completely online and includes a very quick and fair peer-review system, which is all easy to use. Visit $\mathrm{http}: / / \mathrm{www}$. dovepress.com/testimonials.php to read real quotes from published authors. 